\title{
Metode Regresi Extended Cox dalam Survival Analysis pada Penderita Kanker Serviks
}

\author{
Rita Sahara*, Muhammad Nadjib Bustan, \& Ruliana
}

Program Studi Statistika, Fakultas Matematika dan Ilmu Pengetahuan Alam, Universitas Negeri Makassar, Indonesia

Keywords: Survival Analysis, Regresi Cox , Regresi Extended Cox, Kanker serviks.

\begin{abstract}
:
Survival analysis merupakan salah satu metode statistika yang sering digunakan untuk menganalisis data yang berhubungan dengan waktu kejadian. Waktu survival didefiniskan sebagai waktu bertahan suatu objek pada awal pengamatan hingga terjadinya suatu peristiwa (event or end-event). Salah satu tujuan dari analisis survival adalah mengetahui hubungan antara waktu survival dengan variabel independen yang diduga mempengaruhi waktu survivalnya. Hubungan antara waktu survival dan variabel independen dapat dimodelkan dengan menggunakan regresi cox. Dalam penggunaan model regresi cox proportional hazard diasumsikan bahwa variabel independen memenuhi asumsi proportional hazard. Salah satu pendekatan yang digunakan jika asumsi proportional hazard tidak memenuhi adalah pendekatan model regresi extended cox. Data yang digunakan dalam penelitian ini adalah data pasien kanker serviks di RSUD Kota Makassar Tahun 2017-2018. Data kanker serviks memiliki karakteristik yang memungkinkan untuk dilakukan analisis dengan menggunakan regresi extended cox. Adapun hasil analisis yang diperoleh variabel phlebitis tidak memenuhi asumsi proportional hazard, hal ini mengindikasikan bahwa variabel phlebitis bergantung pada waktu. Variabel yang signifikan mempengaruhi laju kesembuhan penderita kanker serviks adalah jenis pengobatan operasi dan phlebitis, dimana jenis pengobatan operasi memiliki probabilitas kesembuhan 13,90 kali lebih besar dibandingkan dengan pasien yang menggunakan jenis pengobatan lain. Sedangkan penderita kanker kanker serviks mengalami kejadian phebitis memiliki probablitias kesembuhan 0,39 kali lebih kecil dibandingkan dengan pasien yang tidak mengalami kejadian phlebitis.
\end{abstract}

\section{Pendahuluan}

Survival Analysis merupakan salah satu metode statistika yang sering digunakan untuk menganalisis data yang berhubungan dengan waktu kejadian. Waktu survival didefiniskan sebagai waktu bertahan suatu objek pada awal pengamatan hingga terjadinya suatu peristiwa (event or end-event) (Collett \& Kimber, 2013). Event yang dimaksud berupa kematian, kesembuhan, respon terhadap pengobatan, dan kejadian lainnya. Tujuan dari analisis survival adalah mengetahui hubungan antara waktu survival dengan variabel independen yang diduga mempengaruhi waktu survival- nya.

Hubungan antara waktu survival dan variabel independen dapat dimodelkan dengan menggunakan regresi cox. Regresi cox atau dikenal dengan model cox proportional hazard merupakan model yang cukup populer digunakan karena tidak ada asumsi yang mendasari distribusi waktu survival-nya. Menurut Collect dan Kimber (2013) model ini digunakan untuk mengetahui hubungan antara variabel dependen dengan variabel independen.

\footnotetext{
* Corresponding author.

E-mail address: ritasahara997@gmail.com
} 
Dalam penggunaan model regresi cox proportional hazard diasumsikan bahwa variabel independen memenuhi asumsi proportional hazard. Artinya bahwa hazard ratio untuk suatu individu sebanding dengan individu yang lain, sehingga perbandingannya konstan sepanjang waktu. Namun kenyatannya, terkadang ditemukan kasus dimana terdapat variabel independen yang tidak memenuhi asumsi proportional hazard. Apabila asumsi cox proportional hazard tidak terpenuhi dalam memodelkan regresi cox, berarti komponen linear yang membentuk model dalam berbagai waktu tidak sesuai. Hal ini mengindikasikan bahwa penggunaan model regresi cox proportional hazard tidak tepat digunakan. Oleh karena itu, diperlukan model lain guna mendapatkan hasil yang lebih baik. Salah satu model yang dapat digunakan adalah model regresi extended cox.

Model regresi extended cox merupakan perluasan dari model cox proportional hazard. Model ini melibatkan variabel terhadap waktu $(t)$. Variabel ini disebut sebagai variabel bergantung waktu (time dependent variable). Variabel bergantung didefiniskan sebagai variabel yang nilainya bisa berubah pada setiap waktunya (Kleinbaum \& Klein, 2005). Variabel independen yang bergantung akan diinteraksikan dengan fungsi waktu $g(t)$. Sehingga dapat dikatakan bahwa penggunaan model regresi extended cox terdapat variabel time dependent variable.

Analisis survival dengan model regresi extended cox banyak digunakan dalam bidang kesehatan. Data kesehatan pada penelitian ini adalah data penyakit kanker serviks. Kanker leher rahim (serviks uterus) atau dikenal dengan kanker serviks merupakan salah satu penyakit yang banyak diderita oleh wanita. Di Indonesia penyakit ini cukup sering ditemukan dikalangan wanita, dimana jenis penyakit ini mempunyai tingkat keganasan yang tinggi (Bustan, 2015).

Menurut Yayasan Kanker Indonesia tahun 2013 bahwa setiap hari muncul sekitar 40 sampai dengan 45 jumlah kasus baru dan sekitar 20 sampai dengan 25 orang diantaranya meninggal. Hal tersebut memberikan gambaran tentang banyaknya wanita yang menderita penyakit ini. Sehingga perlu upaya serius untuk menanganinya. Keberhasilan penyakit ini salah satunya dapat dillakukan dengan mengidentifikasi faktor-faktor yang berpengaruh terhadap kesembuhan hidup penderita.

\section{Tinjauan Pustaka}

\subsection{Survival Analysis}

Survival Analysis merupakan kumpulan prosedur statistika yang digunakan untuk menganalisis data dimana outcome variabel yang diperhatikan adalah waktu sampai terjadinya suatu kejadian (event) yang diharapkan. Suatu event dilambangkan dengan simbol $d$ dengan mendefiniskan status event. Nilai $d=1$ menunjukkan event (peristiwa) dan $\mathrm{d}=0$ menunjukkan tersensor. Menurut Kleinbaum dan Klein (2005) beberapa tujuan analisis survival adalah sebagai berikut:

a. Mengestimasi dan menginterprestasi fungsi survival dan fungsi hazard dari data survival.

b. Membandingkan fungsi survival dan fungsi hazard.

c. Mengetahui pengaruh dari variabel independen terhadap waktu survival.

Kleinbaum dan Klein (2005) membagi tiga point penting yang harus diperhatikan dalam menentukan waktu survival, diantaranya :

a. Time Original or Starting Point (titik awal) yakni waktu dimulainya suatu penelitian

b. Ending Event of Interest (kejadian akhir) yakni kejadian yang menjadi inti dari penelitian.

c. Measurement Scale for the Passage of Time (skala ukuran untuk berlalunya waktu)

Dalam analisis survival sangat mempertimbangkan yang namanya penyensoran. Data dikatakan tersensor jika data (objek penelitian) yang waktu terjadinya suatu peristiwa tidak diketahui secara pasti. Collett dan Kimber (2013) membagi penyensoran menjadi tiga bagian yakni diantaranya :
a. Sensor Kiri
b. Sensor Kanan
c. Sensor Interval 


\subsection{Fungsi Survival dan Fungsi Hazard}

Fungsi survival $S(t)$ didefinisikan sebagai probabilitas suatu objek bertahan setelah waktu ke-t, persamaan dapat dituliskan sebagai berikut :

$$
\begin{aligned}
& S(t)=P(\text { individu dapat bertahan lebih dari waktu } t) \\
& S(t)=P(T \geq t) \\
& S(t)=\int_{t}^{\infty} f(t) d t
\end{aligned}
$$

Dengan fungsi kumulatif distribusi $F(t)=P(T \leq t)$, sehingga survival function dinyatakan sebagai berikut :

$$
\begin{aligned}
S(t) & =1-P \text { (individu yang mati setelah waktu } t) \\
S(t) & =1-P(T \leq t) \\
S(t) & =1-F(t) \\
F(t) & =1-S(t) \\
\frac{d(F(t))}{d t} & =\frac{d(1-S(t))}{d t} \\
f(t) & =-\frac{d(S(t))}{d t}=-S^{\prime}(t)
\end{aligned}
$$

Fungsi hazard dinotasikan dengan $h(t)$. Fungsi ini didefiniskan sebagai probabilitas suatu individu mengalami kejadian (event) dalam interval waktu yang sangat pendek dari $t$ sampai $t+\Delta t$, dengan asumsi bahwa individu tersebut mampu bertahan hidup hingga waktu $t$ (Hutahaen dkk, 2014). Fungsi $h(t)$ dari waktu bertahan hidup $T$ memiliki fungsi yang persamaan sebagai berikut:

$$
\begin{gathered}
\text { P\{individu yang bertahan hingga waktu } t \\
h(t)=\lim _{\Delta t \rightarrow 0} \frac{\text { mengalami kejadian pada interval }(t, t+\Delta t)\}}{\Delta t} \\
h(t)=\lim _{\Delta t \rightarrow 0} \frac{P(t \leq T<t+\Delta t \mid T \geq t)}{\Delta t}
\end{gathered}
$$

\subsection{Asumsi Proportional Hazard}

Dalam model regresi cox proportional hazard asumsi yang harus dipenuhi adalah asumsi cox proportional hazard. Asumsi proportional hazard (PH) sangat penting dalam analisis survival. Asumsi dikatakan terpenuhi jika hazard rate dari dua pengamatan nilainya konstan dari waktu ke waktu selama pengamatan berlangsung atau dengan kata lain kurva survival (antar kelompok pengamatan) tidak saling berpotongan (Afifa \& Purnami, 2016). Ada tiga jenis pendekatan asumsi Proportional Hazard adalah sebagai berikut (Dahlan,2013) :

a. Garis Survival pada Kurva Kaplan - Meier yang tidak saling berpotongan (pendekatan grafik).

b. Garis survival pada ln-ln survival tidak saling berpotongan.

c. Global test atau Goodness of Fit (GOF).

Dari ketiga jenis pengecekan asumsi proportional hazard (PH), pada penelitian ini menggunakan pengecekan asumsi global test. Pengecekan asumsi PH dapat dilakukan sebagai berikut:

Hipothesis dari uji global test adalah sebagai berikut :

H0: Data memenuhi asumsi PH

H1: Data tidak memenuhi asumsi PH Taraf signifikansi $\alpha: 0,05$

Penolakan $H 0$ jika $p-$ value $<\alpha$ artinya data tidak memenuhi asumsi PH. 


\subsection{Model Regresi Extended Cox}

Model regresi extended cox merupakan perluasan dari model cox proportional hazard. Dalam model regresi extended cox terdapat variabel yang melibatkan waktu $(t)$. Variabel ini dikenal dengan vaiabel bergantung waktu (timedependent variabel). Variabel tergantung waktu didefinisikan sebagai variabel yang nilainya mungkin berbeda seiring waktu (Kleinbaum \& Klein, 2005). Variabel yang bergantung pada waktu diinteraksikan dengan fungsi waktu $g(t)$. Fungsi waktu biasa dilambangkan dengan $t, \ln t$, dan fungsi lain yang mengandung $t$. Variabel yang bergantung pada waktu diinteraksikan dengan fungsi waktu $g(t)$. Persamaan umum dari model extended cox dituliskan sebagai berikut:

$$
h(t, \boldsymbol{X}(t))=h_{0}(t) \exp \left[\sum_{i=1}^{p 1} \beta_{i} X_{i}+\sum_{j=1}^{p 2} \delta_{j} X_{j}(t)\right]
$$

dengan :

$h(t, \boldsymbol{X}(t))$ : fungsi hazard yang menambahkan variabel bergantung waktu.

$h_{0}(t) \quad$ : fungsi hazard dasar (baseline hazard function)

$\delta_{j} \quad$ : koefisien $\mathrm{X}$ yang diinteraksikan dengan fungsi waktu.

$X_{j}(t) \quad:$ variabel independent yang diinteraksikan $\mathrm{s}$

$p 1 \quad$ : banyaknya variabel independenyang memenuhi asumsi

$\quad \quad 2 \quad$ : banyaknya variabel independen yang tidak memenuhi asumsi $\mathrm{PH}$

$\beta_{i} \quad:$ Parameter regresi

$X_{i} \quad$ : variabel independen

Asumsi dari model ini adalah pengaruh time dependent $X_{j}(t)$ terhadap peluang bertahan pada saat $t$. Model extended cox hanya menyediakan satu untuk koefisien variabel time dependent, yang berarti koefisien berlaku untuk setiap $t$ dari $X_{j}(t)$ selama masa penelitan berlangsung. Menurut Ata dan Sozer (2007) Terdapat empat jenis bentuk fungsi terhadap waktu diantaranya :

$g_{b}(t)=0$ (bentuk yang paling sederhana sehingga menghasilkan model cox proportional hazard).

$g_{b}(t)=t$ (jika hasil pengujian $\delta b$ signifikan maka model extended cox lebih baik digunakan dari model cox proportional hazard sehinga hazard ratio merupakan fungsi terhadap waktu)

$g_{b}(t)=\log t$

$g_{b}(t)=$ fungsi Heaviside.

Jika $x_{1}, x_{2}, \ldots, x_{p 1}$ adalah variabel time-independent yang memenuhi asumsi proportional hazard dan $x_{p_{1+1}}, x_{p_{2+2}}, \ldots, x_{p_{2}}$ adalah variabel time-independent yang tidak memenuhi asumsi proportional hazard serta $x_{1}\left(t_{j}\right), x_{2}\left(t_{j}\right), \ldots, x_{p_{2}}\left(t_{j}\right)$ adalah variabel time-dependent. Maka persamaan model extended cox dituliskan sebagai berikut:

$$
\mathrm{h}(\mathrm{t}, \mathrm{X}(\mathrm{t}))=h_{0}(\mathrm{t}) \exp \left[\sum_{a=1}^{p 1} \beta_{a} X_{a}+\sum_{b=p 1+1}^{p 2} \beta_{b} X_{b}+\sum_{b=p 1+1}^{p 2} \delta_{b} X_{b}\left(t_{j}\right)\right]
$$

Hazard ratio pada model regresi extended cox sama halnya pada model cox proportional hazard, namun memiliki spesifik pada waktu tertentu.

$$
\begin{aligned}
\widehat{H R}(t) & =\frac{\hat{h}\left(t, \boldsymbol{X}^{*}(t)\right)}{\hat{h}(t, \mathbf{X}(t))} \\
& =\exp (\hat{\beta}+\hat{\delta})
\end{aligned}
$$

\section{Metode Penelitian}

Jenis penelitian yang digunakan adalah penelitian kuantitatif dengan mengambil dan mengumpulkan data serta menganalisis dengan menggunakan model Regresi Extended Cox. Data yang digunakan dalam penelitian ini adalah data sekunder, berupa data rekam medis pasien kanker serviks di RSUD Kota Makassar Tahun 2017-2018. 
Tabel 1 Variabel Penelitian

\begin{tabular}{|c|c|c|}
\hline Variabel & Nama Variabel & Deskriptif \\
\hline $\mathrm{Y}$ & Waktu survival (T) & $\begin{array}{l}\text { Waktu selama pasien kanker menjalani perawatan di } \\
\text { rumah sakit hingga dinyatakan sembuh. }\end{array}$ \\
\hline $\mathrm{X} 1$ & Usia (Tahun) & $\begin{array}{l}\text { Usia dari pasien } \\
1 \leq 45 \\
2>45\end{array}$ \\
\hline $\mathrm{X} 2$ & Stadium & $\begin{array}{l}1=\text { Stadium I } \\
2=\text { Stadium II } \\
3=\text { Stadium III } \\
4=\text { Stadium IV }\end{array}$ \\
\hline $\mathrm{X} 3$ & Jenis Pengobatan & $\begin{array}{l}1=\text { Kemoterapi } \\
2=\text { Transfusi PRC } \\
3=\text { Operasi } \\
4=\text { Kemoterapi dan Transfusi PRC }\end{array}$ \\
\hline $\mathrm{X} 4$ & Penyakit Penyerta & $\begin{array}{l}0=\text { Tidak } \\
1=\text { Ya }\end{array}$ \\
\hline X5 & Komplikasi & $\begin{array}{l}0=\text { Tidak Komplikasi } \\
1=\text { Ada Komplikasi }\end{array}$ \\
\hline $\mathrm{X} 6$ & Flebitis & $\begin{array}{l}0=\text { Tidak } \\
1=\text { Ya }\end{array}$ \\
\hline
\end{tabular}

Adapun langkah-langkah teknik analisis yang akan dilakukan dalam penelitian ini :

1. Eksplorasi data

a. Penentuan titiak awal (time origin or starting point) dan kejadian akhir (ending event of Interets) dalam penelitian. Titik awal adalah waktu masuk pasien kanker serviks rawat inap di Rumah Sakit sedangkan kejadian akhir adalah waktu pasien rawat inap dinyatakan keluar dari Rumah Sakit.

b. Skala pengukuran yang digunakan dalam penelitian adalah satuan hari.

2. Sensor pada penelitian ini adalah sensor kanan dimana kondisi pasien dinyakatakan berhenti atau pindah pengobatan dan meninggal karena penyakit yang lain.

3. Menguji asumsi Proportional Hazard pada variabel independen yang diduga mempengaruhi ketahanan hidup kanker serviks menggunakan pendekatan uji Goodness of Fit untuk mengetahui apakah secara statistika asumsi proportional hazard terpenuhi. Kemudian mengindentifikasi variabel independen yang tidak memenuhi asumsi propotional hazard.

4. Pemodelan laju kesembuhan pasien kanker menggunakan regresi extended cox. Adapun tahapan pemodelannya sebagai berikut :

a. Menentukan fungsi waktu yang digunakan sebagai interaksi waktu.

b. Pendugaan dan Pengujian Model Regresi Extended Cox

5. Menghitung Hazard Ratio.

6. Interpretasi model regresi extended cox.

7. Kesimpulan

\section{Hasil dan Pembahasan}

\subsection{Statistika Deskriptif}

Analisis statistika deskriptif variabel-variabel yang digunakan pada penelitian pemodelan laju kesembuhan penderita kanker serviks, disajikan dalam bentuk tabel dan gambar dengan 47 pasien di RSUD Kota Makassar Tahun 20172018. 
Tabel 2 Statistika Deskriptif Pasien Kanker Serviks

\begin{tabular}{lccc}
\hline Variabel & Minimum & Maksimum & Rerata \\
\hline Waktu & 1 & 20 & 8 \\
Usia & 30 & 67 & 50 \\
\hline
\end{tabular}

Tabel 2 dilihat bahwa pasien penderita kanker serviks menerima perawatan paling cepat 1 hari dan paling lambat 20 hari, rata-rata penderita kanker serviks memiliki lama perawatan selama 8 hari. Sedangkan pada usia penderita kanker serviks paling rendah adalah 30 tahun dan usia tertinggi adalah 67 tahun dengan rata-rata usia pasien penderita kanker serviks di RSUD Kota Makassar adalah 50 tahun

Tabel 3 Persentase Pasien Kanker Serviks

\begin{tabular}{|c|c|c|c|}
\hline & Variabel & Frekuensi & Presentase \\
\hline \multirow{4}{*}{ Stadium } & Stadium 1 & 7 & $15 \%$ \\
\hline & Stadium 2 & 21 & $45 \%$ \\
\hline & Stadium 3 & 19 & $44 \%$ \\
\hline & Stadium 4 & 0 & $0 \%$ \\
\hline \multirow{4}{*}{$\begin{array}{l}\text { Jenis } \\
\text { Pengobatan }\end{array}$} & Kemoterapi & 20 & $41 \%$ \\
\hline & Operasi & 8 & $16 \%$ \\
\hline & Transfusi PRC & 18 & $37 \%$ \\
\hline & Kemoterapi dan Transfusi & 3 & $6 \%$ \\
\hline \multirow{2}{*}{$\begin{array}{l}\text { Penyakit } \\
\text { Penyerta }\end{array}$} & $\mathrm{Ya}$ & 1 & $2 \%$ \\
\hline & Tidak & 46 & $98 \%$ \\
\hline \multirow{2}{*}{ Komplikasi } & $\mathrm{Ya}$ & 1 & $2 \%$ \\
\hline & Tidak & 46 & $98 \%$ \\
\hline \multirow{2}{*}{ Phlebitis } & $\mathrm{Ya}$ & 37 & $79 \%$ \\
\hline & Tidak & 10 & $21 \%$ \\
\hline Total & & & $100 \%$ \\
\hline
\end{tabular}

\subsection{Pengujian Asumsi Cox Proportional Hazard Pada Data Penderita Kanker Serviks}

Dikatakan asumsi terpenuhi jika $p$-value $>\alpha(0,05)$. Pengujian asumsi metode ini menghasilkan $p$-value pada setiap faktor yang diduga mempengaruhi laju kesembuhan penderita kanker serviks, ditunjukkan pada Tabel 4.4 berikut ini.

Tabel 4 Pengujian Asumsi Proportional Hazard dengan uji GOF

\begin{tabular}{llccl}
\hline Variabel & & Korelasi & p-value & Ket \\
\hline Usia (X1) & & $-0,1630$ & 0,2818 & Gagal tolak $\mathrm{H}_{0}$ \\
\hline Stadium (X2) & Stadium (2) & 0,0107 & 0,9404 & Gagal tolak $\mathrm{H}_{0}$ \\
& Stadium (3) & 0,0971 & 0,4996 & Gagal tolak $\mathrm{H}_{0}$ \\
\hline Jenis Pengobatan (X3) & Operasi & 0,8810 & 0,5688 & Gagal tolak $\mathrm{H}_{0}$ \\
& Transfusi PRC & 0,0944 & 0,5276 & Gagal tolak $\mathrm{H}_{0}$ \\
& Kemo dan Transfusi & 0,1093 & 0,4501 & Gagal tolak $\mathrm{H}_{0}$ \\
\hline Penyakit Penyerta (X4) & & 0,1769 & 0,9999 & Gagal tolak $\mathrm{H}_{0}$ \\
\hline Komplikasi (X5) & & 0,0918 & 0,5405 & Gagal tolak $\mathrm{H}_{0}$ \\
\hline Phlebitis (X6) & & $-0,2797$ & 0,0464 & Tolak $\mathrm{H}_{0}$ \\
\hline
\end{tabular}

Berdasarkan Tabel 4 diatas diketahui bahwa variabel Phlebitis tidak memenuhi asumsi proportional hazard, yang menunjukkan bahwa variabel phlebitis pada penderita kanker serviks tidak memenugi asumsi proportional hazard. 
4.3. Estimasi Parameter Regresi Extended Cox Data Penderita Kanker Serviks

Tabel 5 Estimasi Parameter Model Regresi Extended Cox

\begin{tabular}{lcccl}
\hline Variabel & & $\begin{array}{c}\text { Estimasi } \\
\text { Parameter }\end{array}$ & P-value & Ket \\
\hline Usia (X1) & 0,519 & 0,2658 & Tidak signifikan \\
\hline Stadium $(\mathrm{X} 2)$ & Stadium 2 & 0,227 & 0,7764 & Tidak signifikan \\
& Stadium 3 & 0,303 & 0,6622 & Tidak signifikan \\
\hline Jenis & Operasi & $-1,970$ & 0,0055 & signifikan \\
Pengobatan $(\mathrm{X} 3)$ & Transfusi PRC & $-0,474$ & 0,3534 & Tidak signifikan \\
& Kemo dan transfusi & $-0,165$ & 0,8389 & Tidak signifikan \\
\hline Penyakit Penyerta $(\mathrm{X} 4)$ & $-16,30$ & 0,9974 & Tidak signifikan \\
\hline Komplikasi (X5) & 0,215 & 0,8587 & Tidak signifikan \\
\hline Phlebitis (X6) & 8,850 & $<0,001$ & signifikan \\
\hline g(t).Phlebitis (X6) & $-0,957$ & $<0,001$ & signifikan \\
\hline
\end{tabular}

Berdasarkan Tabel 5 dilakukan dengan pengujian serentak, sehingga didapatkan nilai estimasi parameter dan $p$-value, dengan $\alpha$ sebesar 0,05. Dari hasil pengujian serentak yang dilakukan dapat disimpulkan bahwa keputusan Tolak $\mathrm{H}_{0}$ yang berarti minimal terdapat satu variabel yang berpengaruh signifikan terhadap laju kesembuhan pada penderita kanker serviks. Model regresi extended cox pada laju kesembuhan penderita kanker serviks menggunakan fungsi t sebagai fungsi waktu, sehingga didapatkan model sebagai berikut :

$$
\begin{aligned}
\hat{h}(t, x(t))=\hat{h}_{0}(t) & \exp (0,519 \text { Usia }+0,227 \text { Stadium } 2+0,303 \text { Stadium } 3-1,970 \text { Jenis Pengobatan operasi } \\
& -0,474 \text { Jenis Pengobatan transfusi PRC }-0,165 \text { Jenis Pengobatan kemo dan transfusi } \\
& -16,30 \text { Penyakit Penyerta }+0,215 \text { Komplikasi }+8,850 \text { Phebitis }-0,957(\text { Plebitis } * \mathrm{~g}(\mathrm{t}))
\end{aligned}
$$

Setelah mendapatkan model dan mengetahui variabel mana saja yang signifikan mempengaruhi laju kesembuhan penderita kanker serviks, selanjutnya akan dikeluarkan variabel yang tidak signifikan dan akan dimodelkan kembali regresi extended cox dengan uji parsial, dimana hanya mengandung variabel yang signifikan saja, ditunjukkan pada tabel 6.

Tabel 6 Estimasi Parameter Pada Variabel yang Signifikan

\begin{tabular}{lcc}
\hline Variabel & Estimasi Parameter & p-value \\
\hline Jenis Pengobatan Operasi (X3) & $-2,3153$ & 0,00099 \\
\hline Phlebitis (X6) & 8,7467 & $<0,0001$ \\
\hline $\mathrm{g}(\mathrm{t}) *$ Phlebitis (X6) & $-0,9602$ & $<0,0001$ \\
\hline
\end{tabular}

Berdasarkan hasil estimasi parameter pada Tabel 6 diperoleh model Regresi Extended Cox sebagai berikut :

$$
\hat{h}(t, x(t))=\hat{h}_{0}(t) \exp (-2,3153 \text { jenis pengobatan operasi }+8,7467 \text { phlebitis }-0,9602 \text { phebitis } * g(t))
$$

Dari Tabel 6 dilihat bahwa variabel jenis pengobatan operasi dan Phlebitis berpengaruh signifikan pada laju kesembuhan penderita kanker serviks Dari model diatas dapat di interpretasikan bahwa variabel jenis pengobatan operasi dan phlebitis signifika terhadap mempengaruhi laju kesembuhan penderita pasien kanker serviks. 


\subsection{Hazard Ratio Pada Data Penderita Kanker Serviks}

Tabel 7 Nilai Hazard Ratio

\begin{tabular}{lc}
\hline Variabel & Hazard Ratio $\left(\boldsymbol{e}^{-\boldsymbol{\beta}}\right)$ \\
\hline Phlebitis $(\beta)$ & 0,0069 \\
\hline $\mathrm{g}(\mathrm{t})$ *phlebitis $(\delta)$ & 0,3840 \\
\hline$(\beta+\delta)$ & 0,39 \\
\hline Jenis Pengobatan Operasi & 13,90 \\
\hline
\end{tabular}

Berdasarkan tabel 6 diketahui bahwa hazard ratio dari model regresi extended cox pada penderita kanker serviks, dimana jumlah dari nilai hazard ratio dari variabel Phlebitis dan hasil interaksi waktu adalah 0,39, sehingga dapat disimpulkan bahwa penderita yang mengalami kejadian Phlebitis memiliki probabilitas kesembuhan 0,39 kali lebih kecil dibandingkan dengan pasien yang tidak mengalami kejadian phlebitis dan dapat menambah lamanya perawatan pada pasien penderita kanker serviks. Sedangkan pada penderita yang menggunakan jenis pengobatan operasi memiliki probabilitas kesembuhan 13,90 kali lebih besar dibandingkan dengan pasien yang menggunakan jenis pengobatan lain.

\section{Kesimpulan}

Berdasarkan hasil dan pembahasan mengenai pemodelan regresi extended cox pada penderita kanker serviks di RSUD Makassar, maka dapat disimpulkan bahwa pemodelan regresi extended cox pada data pasien penderita kanker serviks di RSUD Kota Makassar sebagai berikut:

$$
\hat{h}(t, x(t))=\hat{h}_{0}(t) \exp (-2,3153 \text { jenis pengobatan operasi }+8,7467 \text { phlebitis }-0,9602 \text { phebitis } * g(t))
$$

Dari hasil penelitian ini dijelaskan bahwa terdapat beberapa faktor yang signifikan terhadap laju kesembuhan penderita kanker serviks yakni Phebitis, jenis pengobatan operasi dan interaksi antara phlebitis dengan waktu survival signifikan, hal ini menunjukkan bahwa penderita kanker serviks yang mengalami kejadian phlebitis memiliki probabilitas kesembuhan hidup yang berbeda-beda.

\section{References}

Afifa, A. N., \& Purnami, S. W. (2016). Uji Proportional Hazard pada Data Penderita Kanker Serviks di RSUD dr. Soetomo Surabaya. Jurnal Sains dan Seni ITS Vol.5 No.1 , 2337-3520.

Ata, N., \& Sozer, M. T. (2007). Cox Regression Models With Nonproportional Hazard Applied To Lung Cancer Survival Data. Hacettepe Journal of Mathematics and Statistics 36 (2), 156-167.

Adharina, T. W., \& Purnami, S. W. (2017). Pemodelan Kekambuhan Pasien Kanker Serviks di RSUD dr. Soetomo Surabaya Menggunakan Regresi Cox Extended. SAINS DAN SENI ITS 6 (2), 2337-2520.

Bustan, M. N. (2015). Manajemen Pengendalian Penyakit Tidak Munular. Jakarta: Rineka Cipta.

Collett, D., \& Kimber, A. (2013). Modelling Survival Data in Medical Research Third Edition. Bristol, UK: CRC Press. Dahlan.M.S (2013)., Analisis Survival "Dasar-DAsar Teori dan Aplikasi Program Stata".Sagung Seto : Jakarta.

Hutahaen, L. P., Mukid, M. A., \& Wulandari, T. (2014). Model Regresi Cox Proportional Hazard Pada Data Lama Studi Mahasiswa (Studi KAsus Di Fakultas Sains dan Matematika Universitas Dipenogero Semarang Mahasiswa Angkatan 2009). Jurnal Gaussian, Volume 3, Nomor 2 ISSN: 2339-2541, 175-181.

Irmayani.,(2017) Pemodelan Kelulusan Tepat Waktu Mahasiswa Sekolah Pascasarjana Institut Pertanian Bogor.Tesis.IPB.

Kleinbaum, D. G., \& Klein, M. (2005). Survival Analysis: A Self-Learning Text, Second Edition (Statistics for Biology and Health). USA: Springher.

Lee, E. T., \& Wang, J. (2003). Statistical Methods For Survival Data Analysis. Oklahoma: J. Wiley.

Maryama, A. (2016). Model Regresi Stratified Cox dan Extended Cox untuk Mengatasi Non Proportional Hazard. Tesis ITS.

Yayasan Kanker Indonesia. (2013) Press Release Training of Trainer Pap Tes and IVA Serviks. 